\title{
Environmental Quality Predicts Optimal Egg Size in the Wild
}

\author{
Njal Rollinson $^{1, \star}$ and Jeffrey A. Hutchings ${ }^{1,2}$ \\ 1. Department of Biology, Dalhousie University, Halifax, Nova Scotia B3H4R2, Canada; 2. Centre For Ecological and Evolutionary \\ Synthesis, Department of Biology, University of Oslo, NO-0316 Oslo, Norway
}

Submitted October 19, 2012; Accepted February 27, 2013; Electronically published May 22, 2013

Online enhancement: appendix. Dryad data: http://dx.doi.org/10.5061/dryad.0q13g.

\begin{abstract}
Parents can maximize their reproductive success by balancing the trade-off between investment per offspring and fecundity. According to theory, environmental quality influences the relationship between investment per offspring and offspring fitness, such that well-provisioned offspring fare better when environmental quality is lower. A major prediction of classic theory, then, is that optimal investment per offspring will increase as environmental quality decreases. To test this prediction, we release over 30,000 juvenile Atlantic salmon (Salmo salar) into eight wild stream environments, and we monitor subsequent growth and survival of juveniles. We estimate the shape of the relationship between investment per offspring (egg size) and offspring fitness in each stream. We find that optimal egg size is greater when the quality of the stream environment is lower (as estimated by a composite index of habitat quality). Across streams, the mean size of stream gravel and the mean amount of incident sunlight are the most important individual predictors of optimal egg size. Within streams, juveniles recaptured in stream subsections that featured larger gravels and greater levels of sunlight also grew relatively quickly, an association that complements our crossstream analyses. This study provides the first empirical verification that environmental quality alters the relationship between investment per offspring and offspring fitness, such that optimal investment per offspring increases as environmental quality decreases.
\end{abstract}

Keywords: parental care, fitness function, environmental variation, body size, investment per offspring, minimum viable offspring size.

\section{Introduction}

Reproductive traits are strongly associated with fitness, and biologists have long endeavored to understand the causes and consequences of variation in these traits. Lack (1947) and Svärdson (1949) first recognized that reproductive effort is finite, such that parents must trade off investment per offspring (e.g., egg or seed size) and fecundity. Interestingly, while fecundity and investment per offspring can never be simultaneously maximized, the strength of the trade-off between fecundity and offspring fitness is tied to environmental quality (e.g., Einum and Fleming 1999). This is be-

\footnotetext{
* Corresponding author; e-mail: njal.rollinson@gmail.com.
}

Am. Nat. 2013. Vol. 182, pp. 76-90. (c) 2013 by The University of Chicago. 0003-0147/2013/18201-54195\$15.00. All rights reserved.

DOI: $10.1086 / 670648$ cause the shape of the relationship between investment per offspring and offspring fitness (i.e., the fitness function) is expected to differ among environments. In low-quality environments, a relatively high level of initial offspring investment might be required just to ensure that offspring have a nonzero chance of survival (McGinley et al. 1987), or the investment per offspring-offspring fitness function might be relatively protracted, increasing incrementally to an asymptote (Hutchings 1997). In either case, well-provisioned offspring are predicted to fare better (Fox et al. 1997; Hutchings 1997; Einum and Fleming 1999), such that parents maximizing fecundity in low-quality environments do so at the expense of offspring fitness (Johnson et al. 2010). On the other hand, both well-provisioned and poorly provisioned offspring fare well in high-quality environments, such that parents can maximize fecundity and offspring fitness simultaneously. Selection ultimately favors parents that balance the fitness gains accrued from increases in fecundity with the fitness losses resulting from investment-related decreases in offspring viability (Smith and Fretwell 1974), such that optimal investment per offspring is predicted to increase as environmental quality decreases.

Although a negative relationship between environmental quality and optimal investment per offspring is widely expected (Hendry et al. 2001; Bashey 2008; Rollinson et al. 2012), support for this prediction is surprisingly limited. While many empirical studies have shown that parents produce relatively well-provisioned offspring in lowquality environments (e.g., Johnston and Leggett 2002; Taborsky 2006; Bashey 2008), few studies have estimated the shape of the fitness function that relates investment per offspring to offspring fitness (for examples, see Hutchings 1991; Sinervo et al. 1992; Einum and Fleming 2000a; Dias and Marshall 2010). In the few instances where these fitness functions have been estimated, optimal investment per offspring has been found to be greater when offspring food rations are lower (e.g., Hutchings 1997) or when competition for resources is higher (e.g., Marshall and Keough 2008, 2009). But none of these studies constitutes a defensible test of the environmental quality hypothesis. 
A fair test requires that the unit of replication is the environment, and inferential statistics must be applied at this level (Hurlbert 1984).

Theoretical models and simulation studies are often used to predict how investment per offspring might evolve in different types of environment (e.g., Parker and Begon 1986; McGinley et al. 1987; Einum and Fleming 2004; Olofsson et al. 2009). However, given that little empirical background exists, many of these models are based on unverified assumptions. For instance, it is not clear whether spatial or temporal differences in optimal investment per offspring at the intraspecific level are consistently associated with changes in minimum viable offspring size (the minimum investment per offspring required to ensure offspring have a nonzero chance of survival), yet this assumption underlies many theoretical models (e.g., McGinley et al. 1987; Einum and Fleming 2004; Olofsson et al. 2009). Therefore, an empirical focus on quantitative descriptions of investment per offspringoffspring fitness relationships, and their comparison across multiple environments, is necessary both to inform theory and to formally test the environmental quality hypothesis. Such a study is multifaceted because the selective agents that constitute "environmental quality" and that ultimately drive the evolution of investment per offspring must be simultaneously identified.

Here, we use a novel method of estimating the relationship between investment per offspring and offspring fitness (Rollinson and Hutchings 2013) to test the prediction that optimal investment per offspring increases as the quality of the offspring environment decreases. We assess the strength of selection on investment per offspring, and whether minimum viable offspring size changes predictably with optimal investment per offspring. Finally, we use direct estimates of optimal values as a means of identifying components of the physical environment that comprise "environmental quality" and potentially drive the evolution of offspring provisioning strategies in the wild.

\section{Study Species and Predictions}

Atlantic salmon (Salmo salar) and its sister species have a long history in the study of investment per offspring. One reason for this is because they provide little postpartum parental care, such that egg size (e.g., egg weight or egg diameter) is a good proxy for the amount of energy invested per offspring. Salmonid fish have been instrumental in providing tests of Smith and Fretwell's (1974) classic model (Hutchings 1991; Einum and Fleming 2000a), and in both developing and testing extensions of classic theory (Hendry et al. 2001; Einum and Fleming 2002; Einum et al. 2002; Rollinson and Hutchings 2010, 2011a).

Juvenile Atlantic salmon (individuals in the first year of life) emerge in spring from their nests in stream gravel. They quickly become territorial, establishing fixed foodbased territories located in sections of stream that feature cover objects, such as pebbles and cobble stones, and adequate water velocities and depths (Steingrimsson and Grant 2003). Growth and survival of juveniles has been linked to these three correlated habitat features (e.g., Nislow et al. 1999; Suttle et al. 2004; Finstad et al. 2007). Canopy closure is a fourth component of the physical environment that negatively impacts both survival and growth through its effects on local productivity (e.g., Murphy et al. 1986; Riley et al. 2009). While juvenile habitat preference within rivers is often predicted by concave preference functions where intermediate velocities, depths, and gravel size (substrate composition) are favored (e.g., Guay et al. 2000; Hedger et al. 2005), habitat suitability at higher ecological scales decreases as gravel size and water velocity decrease and as stream depth increases (Bjornn and Reiser 1991). Therefore, if optimal investment per offspring decreases as the quality of the juvenile environment increases, we predict that optimal egg size for Atlantic salmon will be larger in streams typified by small stream gravel, low water velocity, and greater depth. Finally, we predict that growth of wild juveniles will be positively related to the quality of the environment they occupied within streams. The latter prediction is indented to complement our evaluation of optimal egg size and environmental quality by examining sublethal effects of habitat on performance.

\section{Methods}

\section{Study Area and Populations}

Atlantic salmon populations in the inner Bay of Fundy collapsed in the 1990s, and a captive breeding program was initiated to recover these populations (Fraser et al. 2007). One aspect of this recovery effort involved studying the extent of local adaptation and weighing the relative conservation risks of inbreeding and outbreeding depression in salmon from the Economy River ("Eco"; $45^{\circ} 22^{\prime} \mathrm{N}$, $63^{\circ} 54^{\prime} \mathrm{W}$ ), the Great Village River ("Grv"; $45^{\circ} 22^{\prime} \mathrm{N}$, $63^{\circ} 36^{\prime} \mathrm{W}$ ), and the Stewiacke River ("Stw"; $45^{\circ} 8^{\prime} \mathrm{N}$, $63^{\circ} 22^{\prime} \mathrm{W}$; Houde et al. 2011 $a, 2011 b$ ). All three focal rivers are a part of Nova Scotia's Minas Basin, and the maximum pairwise distance between river mouths is approximately $35 \mathrm{~km}$ (fig. 1). Genetic evidence from neutral markers suggests moderate gene flow among rivers $\left(F_{\mathrm{ST}}\right.$ values: Grv-Stw $=0.0353 ;$ Eco-Grv $=0.0673 ;$ Eco-Stw = 0.0953; Tymchuk et al. 2010), and populations are characterized by similar levels of heterozygosity and gene diversity, although there is evidence that Economy River salmon underwent a recent population bottleneck (table A1; tables A1-A6 are available online). 


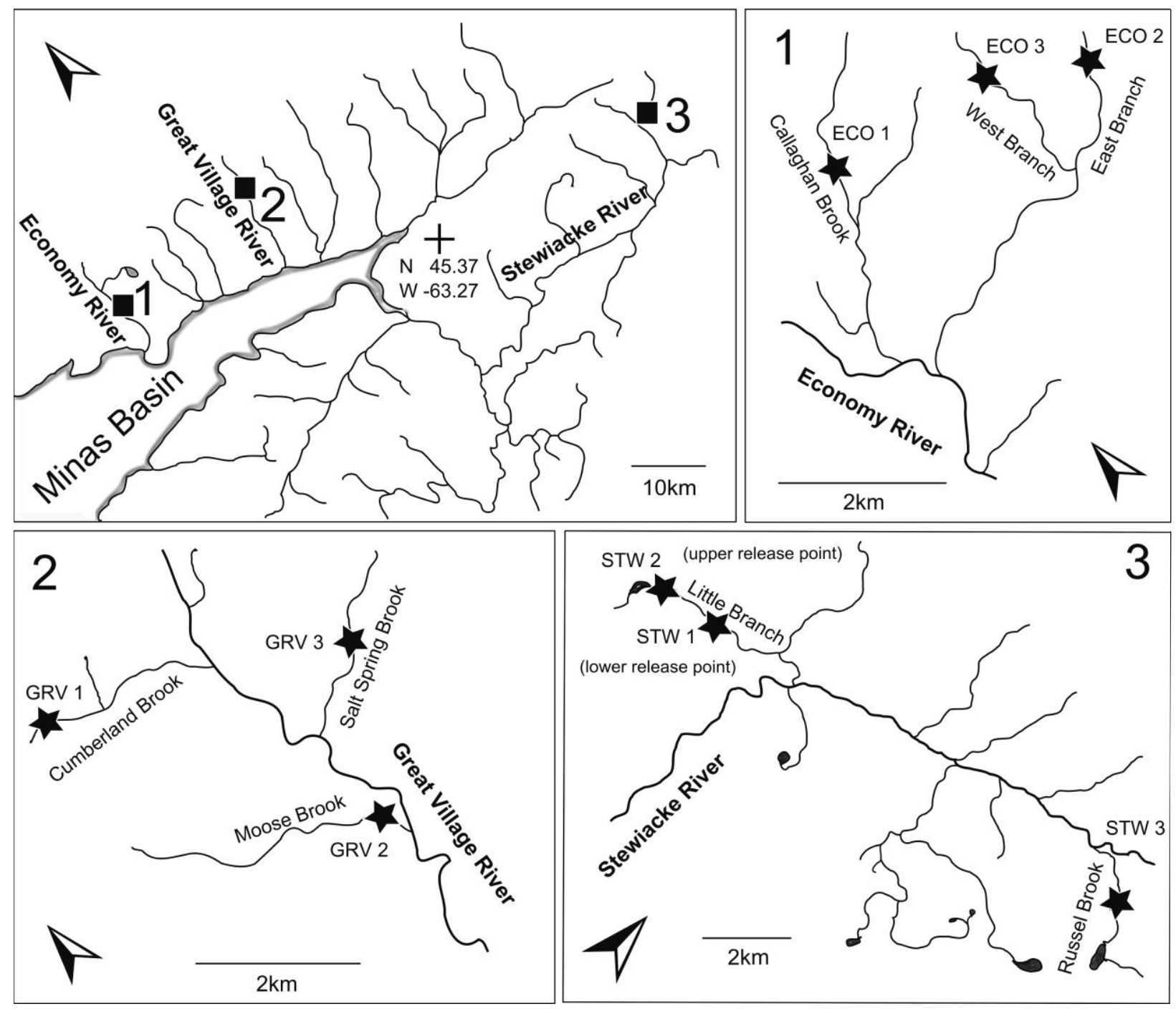

Figure 1: Map of experimental release areas. Dark squares in the top left panel are enlarged in subsequent panels to show location of experimental releases within streams (stars).

Data from a previous release experiment performed in 2008 (Houde et al. 2011a, 2011b), as well as data from the current release experiment, performed in $2009(\mathrm{~N}$. Rollinson, D. M. Keith, A. L. S. Houde, P. V. Debes, M. C. McBride, and J. A. Hutchings, unpublished data), provide little evidence of survival differences between inbred and outbred offspring. In this study, we use data that was collected in 2009 as part of this larger conservation initiative, and we compare the effect of egg size on offspring performance across multiple environments. Importantly, we randomize the genetic contributions of parents with respect to egg size (appendix, available online), and this allows for a robust assessment of the association between egg size per se and offspring fitness.

\section{Breeding Design}

In 2001, the Department of Fisheries and Oceans (DFO) collected 56, 52, and 198 wild juvenile salmon (salmon in their first or second year of life) from the Economy, Great Village, and Stewiacke Rivers, respectively. These wild individuals were reared to maturity in a common environment at the Coldbrook Biodiversity Facility, in Coldbrook, Nova Scotia (details in appendix). These wild individuals were spawned in captivity in 2003 and 2004, and their offspring were reared to maturity in a captive environment through 2008 (fig. A1, available online). All parents used in this study were captive-born fish that had reached sexual 
maturity by 2008 , with the exception of two sires that had been captured in the wild in 2001.

Controlled breeding for this study was performed on October 31, 2008, and November 4, 2008, at Coldbrook. Each dam $(n=45)$ was stripped of her eggs in sequence, and all eggs contained within each dam were divided by eye into four to eight groups of approximately equal number. Each group of eggs was fertilized with sperm from a different sire $(n=49$ sires $)$, such that four to eight halfsib families were produced for each dam; between one and seven of these half-sib families from a given dam were ultimately used in this study. Each half-sib family comprised a particular cross type, and these cross types were defined based on the river of origin of the offspring's grandparents (i.e., wild salmon captured in 2001), and whether the offspring's immediate parents had arisen from breeding wild fish that had been collected from the same or different rivers (fig. A1). In total, 200 families comprising 15 offspring cross types were produced, and a reciprocal breeding design was used such that the same parents contributed to multiple offspring families and cross types (fig. A1; table A3). Between 14 and 25 green eggs (mean $=19.4$ eggs) from each dam were retained at spawning, dried at $50^{\circ} \mathrm{C}$ in a drying oven, and weighed to the nearest $0.1 \mathrm{mg}$ using an electronic balance. Egg size did not differ among dams of different cross types (fig. A2, available online), and egg size varied little within dams (mean \pm SD coefficient of variation in egg size within dams, $8.0 \% \pm 2.9 \%$, range $=$ $2.8 \%-16.7 \%)$. Details on embryo incubation are provided (by Rollinson and Hutchings 2011b).

\section{Experimental Releases and Stream Selection}

Embryo development was complete on May 11, 2009, when offspring spawned on October 31 and November 4, 2008, had reached $100 \%$ and $97 \%$ development, respectively, where $100 \%$ development coincides with first feeding (Kane 1988). Approximately 3,000 unfed juveniles (also called "fry") were then released into each of eight streams, with three release locations in the Stewiacke River, three locations in the Economy River, and three locations in the Great Village River (fig. 1; see also tables A2, A4). Offspring cross types were released into a given river only if a portion of their genome was derived from wild fish originally captured in the river, with the exception of "pure" cross types (i.e., Eco $\times$ Eco, Stw $\times$ Stw, Grv $\times$ Grv), which were released in all rivers (tables A2, A3). All juveniles were released on the same day, and all juveniles were released at the same time and location with streams, with two exceptions: in the stream STW3, juveniles were divided evenly among two adjacent stream sections (the sections converged within $30 \mathrm{~m}$ of the release points), and in STW2, half of the juveniles were released $65 \mathrm{~m}$ downstream from the uppermost release point.

Anecdotal evidence suggests that most streams historically supported naturally spawning Atlantic salmon; however, Minas Basin salmon stocks collapsed in the 1990s, and all streams are now apparently devoid of naturally spawning Atlantic salmon (Fraser et al. 2007). Our releases constituted the only salmon in their first year of life inhabiting each stream, although older salmon (parr aged 1 or 2 years, $6-12$ $\mathrm{cm}$ standard length) from previous release programs inhabited most streams, as did naturally spawned brook trout (Salvelinus fontinalis). Streams were selected for experimental releases based on the average gradient of the land estimated from topographical maps and their close proximity to roads. Site visits were performed in order to ensure that streams were not too wide and not too fast. Based on these subjective criteria, streams were assumed to represent hospitable environments for juvenile Atlantic salmon prior to release, although no direct habitat measurements had been taken before the onset of our study.

\section{Habitat Measurements and Analysis}

In July 2009, habitat stations were established at 5-m intervals in each stream, beginning $10 \mathrm{~m}$ upstream from the release point and ending $500 \mathrm{~m}$ downstream from the release point. At every station, we established a transect that bisected the stream. We recorded water depth using a measuring stick at three equidistant locations along the transect, and then mean water depth was calculated for the transect (depth, $\mathrm{cm}$ ). Stream width (width, $\mathrm{m}$ ) was the linear bankto-bank distance across the transect, measured using a measuring tape. Water velocity (velocity, $\mathrm{m} \mathrm{s}^{-1}$ ) was estimated by calculating the time it took an orange to travel $2 \mathrm{~m}$ in the fastest part of the current (following Purchase and Hutchings 2008), beginning at the transect bisection. At the center of each transect, we measured the proportion of a given area in which sunlight was directly obstructed by physical objects (e.g., leaves, trunks, branches) using a convex densitometer; this measure is expressed as the proportion of closed canopy area. Two measures of canopy closure were taken. Low canopy closure is an estimate of the amount of underbrush that inhibited incident sunlight from reaching the stream, such that only obstructions below a height of $3 \mathrm{~m}$ contributed toward the proportion of closed area. High canopy closure is an estimate of the extent to which forest canopy obstructed sunlight, such that only obstructions above a height of $3 \mathrm{~m}$ contributed to the proportion of closed area. Both types of canopy closure were estimated facing each cardinal direction, and then these four estimates were averaged to produce one estimate of high canopy closure per station and one estimate of low canopy closure per station. Substrate type was estimated by eye for a $5-\mathrm{m}$ area 
between each transect, and each transect bisection fell in the middle of this 5-m survey area. Proportional composition of the substratum was estimated to the nearest $5 \%$ following Boudreault's (1984) size classes: class 1 is sand $(<5 \mathrm{~mm})$; class 2 are gravels $(5-40 \mathrm{~mm})$; class 3 are pebbles $(40-80 \mathrm{~mm})$; class 4 are cobbles $(80-250 \mathrm{~mm})$; class 5 are boulders $(250-500 \mathrm{~mm})$; class 6 is bedrock $(>500 \mathrm{~mm})$. The granulometric index (GI) was then calculated as GI = $\Sigma\left(G_{\mathrm{c}} \times G_{\mathrm{u}}\right)$, where GI is the granulometric index of a station, $G_{\mathrm{c}}$ is the granulometric class and $G_{\mathrm{u}}$ is the proportion of the substrate composed of that class (Hedger et al. 2005).

Velocity, depth, and GI of our individual 5-m stream sections were correlated, so we reduced these data by using principal components analysis. We estimated scores for each individual stream section by including $\log$ (velocity), $\log$ (depth), and GI from all 886 habitat stations comprising all eight streams into a single principal components analysis (Levin et al. 2002; Mäki-Petays et al. 2002). The first of the three principal components accounted for $57.3 \%$ of the variation in the data, and this component was positively associated with $\log$ (velocity) and GI and negatively associated with $\log$ (depth) (eigenvalue $=1.72$; factor loadings: $\mathrm{GI}=0.493, \log$ (velocity) $=0.621$, $\log ($ depth $)=-0.610)$. Importantly, this index of habitat quality reflects a continuum between shallow, fast-flowing stream sections composed of larger, heavier gravel (positive principal component scores) representing favorable juvenile habitat (Bjornn and Reiser 1991) and deeper, slowmoving stream sections where smaller gravel accumulated (negative principal components) representing unfavorable juvenile habitat (also see Nislow et al. 1999; Guay et al. 2000; Suttle et al. 2004; Armstrong and Nislow 2006; Finstad et al. 2007). Principal component scores for each of our eight streams were obtained by dividing the surface area of each $5-\mathrm{m}$ section of stream $(5 \mathrm{~m} \times$ width $)$ by the total area of the stream surveyed (table A5) and then multiplying this value by the principal component score of the stream section and summing all section values within a stream. The mean score of each stream is therefore weighted, such that stream sections contribute in proportion to their area to the overall mean. We note that sites STW1 and STW2 are two independent release sites that are located within the same stream (Little Branch Brook, Stewiacke: upper and lower release sites; see fig. 1), such that these release sites probably do not constitute independent environments. Similarities habitat measurements corroborate this assumption (table A5). We therefore pooled data from these two sites when using inferential statistics to relate stream-specific estimates of optimal egg size (below) to environmental measures, such that only eight "environments" were compared.

\section{Recapture of Juveniles}

Streams were electrofished by a team of three individuals using one backpack electrofisher and a lip-seine net between August 25 and October 3, 2009. Two streams featured beaver dams and exhibited low recapture rates, so to increase sample size these streams were electrofished twice, about 1 month apart (table A4). Electrofishing was initiated at the habitat station furthest from the release point (table A4) and progressed systematically upstream through all areas (except near beaver dams) until we had reached the last station, which was always located $10 \mathrm{~m}$ above the release point. Our maximum survey distances (300-510 $\mathrm{m}$ downstream) extended beyond average downstream dispersal distances of juveniles (Webb et al. 2001; Einum and Nislow 2005). When a juvenile was captured in the seine net, it was placed in a perforated $50-\mathrm{mL}$ vial, and the vial was labeled with the identity of the nearest habitat station. After fishing, juveniles were removed from the vials and anesthetized, using food-safe clove oil (Hilltech Canada, Vankleek Hill, ON). Wet mass was measured to the nearest $0.01 \mathrm{~g}$, and a portion of the tail fin was clipped and placed in an individual $1-\mathrm{mL}$ vial filled with 95\% ethanol. Juveniles were rereleased.

Multiple-pass electrofishing is necessary to reliably estimate survival rates (Bohlin et al. 1989). We performed only single-pass electrofishing, so overall recapture rates at our sites are very likely underestimates of true survival. This does not necessarily pose a problem when estimating optimal egg size: a fitness function can be scaled to any maximum value without fundamentally altering its shape, and it is both the shape of the function and minimum viable egg size that determines optimal egg size (Smith and Fretwell 1974). In this study, we assume that offspring that arising from small eggs were as easy to catch as offspring arising from large eggs, such that the shape of the estimated function is accurate, even if true survival is underestimated (see also Achord et al. 2003; Bailey and Kinnison 2010).

\section{Parentage Assignments}

The parents and grandparents of offspring generated for this study had been previously genotyped at five or more tetranucleotide microsatellite loci (O'Reilly and Harvie 2009; Houde et al. 2011a; also see appendix). Fin clips of juveniles recaptured in our study streams were also genotyped at five to seven tetranucleotide microsatellite loci (for details, see Houde et al. 2011a, 2011b). Based on known genotypes of all dams and sires used in this study, as well as records of mated pairs logged at Coldbrook in autumn of 2008, an exclusion-based macro for Microsoft Excel (C. Harvie, Department of Fisheries and Oceans 
Canada) was used to assign juveniles back to their original family, such that we could identify each juvenile's mother and father. In some cases, juveniles were assigned to more than one family when five loci were used, so these juveniles were genotyped at up to two more loci, and then the assignment was rerun. Familial assignment was over 90\% successful for most streams (table A4).

\section{Estimates of Optimal Egg Size}

We released offspring from a total of 32, 36, and 42 dams into streams in the Great Village, Economy, and Stewiacke Rivers, respectively. The median number of juveniles released per dam ranged from 59 to 81 for the three different rivers. The number of half-sib families released per dam ranged between one and seven (median $=4$ ), although more than one family was released per dam in $87.4 \%$ of cases (table A3). After parentage assignments, we summed the number of juveniles from a given dam (and hence, a given mean egg size) that was released into a stream. Next, we divided this value into the number of offspring recaptured in the stream from that dam. We therefore obtained a continuous recapture probability for each mean egg size in each stream. Logistic regression was used to estimate the relationship between direct estimates of egg size (mg, dry mass) and offspring recapture probability (fitness) for each stream; linear selection differentials $(\beta)$ were also estimated (Lande and Arnold 1983). The egg size-offspring fitness function was estimated for each stream using the Weibull1 model (Rollinson and Hutchings 2013):

$$
f(x)=k \cdot e^{-e^{b \cdot[\ln (x)-\ln (a)]}},
$$

where $k$ is maximum fitness observed in a given stream, $e$ is the base of natural logarithms, ln is the natural logarithm, $b$ is a shape parameter, and $a$ is the inflection point. Weibull-1 models were fit in $R$ (R Development Core Team 2012) with the drc package (Ritz and Strebig 2011). Each level of egg size in these analyses was weighted by the number of individuals originally released from the relevant level of egg size (table A3). Importantly, the Weibull-1 model produces a sigmoidal function, and this reflects a biologically realistic situation in which low but stochastic offspring survival near minimum viable egg size compels the fitness function slowly toward the $X$-axis (Rollinson and Hutchings 2013). No model estimate of minimum viable egg size (i.e., an $x$-intercept) is therefore possible. For each stream, we estimated minimum viable egg size as the predicted value of egg size where survival was 5\% of $k$.

Optimal egg size was derived from the Weibull-1 function following Smith and Fretwell (1974). However, confidence intervals provided by the drc package are valid only when all observations have a common variance, and this assumption could not be satisfied for our data. We therefore used simulation to approximate confidence intervals for optimal egg size estimates. Our simulations first accounted for the uncertainty in the "true" value of offspring survival $(T)$ for a given level of egg size (i) in each stream. While $T_{i}$ was always unknown, our simulation assumes $T_{i}$ falls somewhere within the $95 \%$ confidence limits of the observed recapture rate for every observed level of egg size. We used the binomial distribution to construct $95 \%$ confidence intervals on each observed recapture probability within each stream (Zar 1984, p. 378). One random sample $\hat{p}_{i}$ was obtained from each binomial distribution for each level of egg size within each stream. For the purposes of simulation, $\hat{p}_{i}$ was assumed to accurately represent $T_{i}$ for a given level of egg size. Having obtained one possible value of $T_{\mathrm{i}}$ (namely, $\hat{p}_{i}$ ), we next accounted for the uncertainty estimating $T_{i}$. We parameterized a beta distribution based on the number of recaptures $(\alpha)$ and the number of nonrecaptures $(\beta)$ comprising $\hat{p}_{i}$ (e.g., if $\hat{p}_{i}=0.13$ and 100 fish were released at that level of egg size, then $\alpha=13$ and $\beta=87)$. We drew one random sample $\left(S \hat{p}_{i}\right)$ from the beta distribution of $\hat{p}_{i}$. Finally, all values of $S \hat{p}_{i}$ for a given stream were regressed against dry egg mass using equation (1) to estimate optimal egg size. We repeated this procedure 10,000 times to generate a distribution of optimal egg sizes for each stream. Confidence limits were obtained from the upper and lower $2.5 \%$ of these distributions.

\section{Optimal Egg Size and Environmental Quality}

We used linear regression to test whether optimal egg size was predicted by stream-averaged principal component scores. Values of optimal egg size for streams STW1 and STW2 were estimated from pooled data (as was the principal component score), such that each regression featured eight data points. We further used linear regression to test the relationship between optimal egg size and direct measures of the physical environment: GI, low canopy closure, high canopy closure, velocity, and depth. Stream-averaged estimates of GI, velocity, and depth were calculated within streams as the weighted average of stream sections in which the measurement was taken (weights were determined by the two-dimensional area of each section). Stream-averaged estimates of low canopy closure and high canopy closure were simple averages of closure across stations in a stream. All linear regressions were weighted by the total number of juvenile recaptures in a given stream.

\section{Juvenile Growth Models}

Juveniles often occupy the same territory for at least 2 months in Atlantic Canada (Steingrimsson and Grant 


\section{Proportion of offspring recaptured}

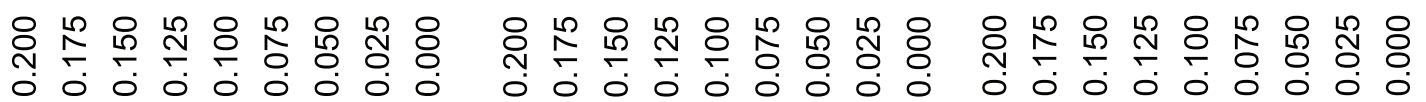
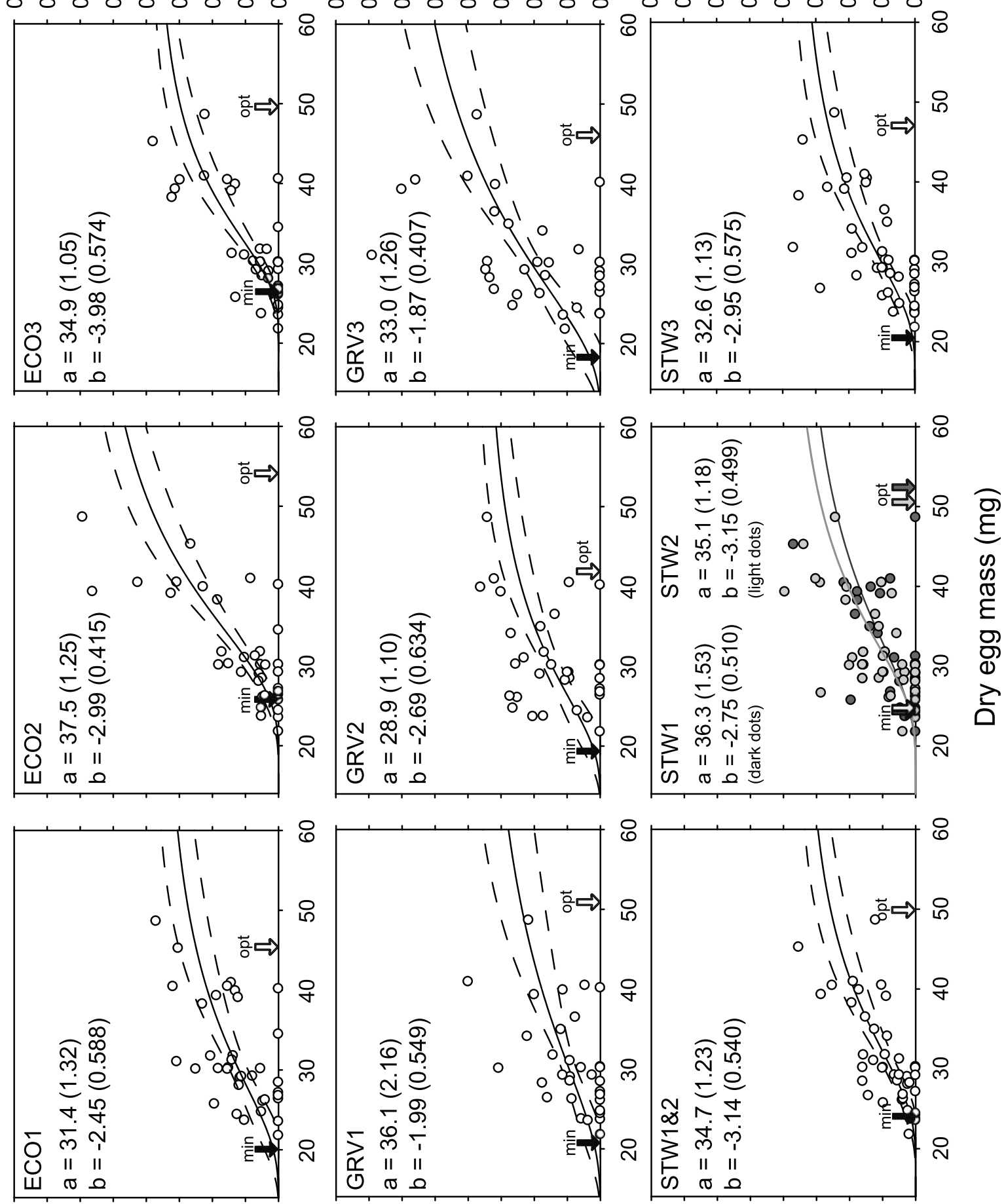

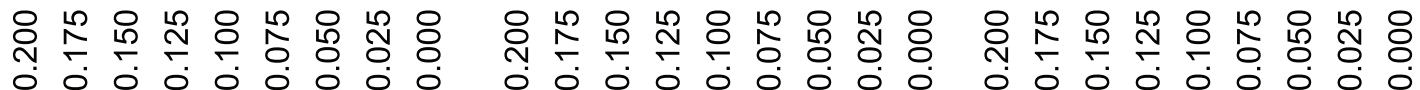

\section{Proportion of offspring recaptured}


2003), so we tested relationships between the physical environment of $5-\mathrm{m}$ stream sections and growth of juveniles that occupied these sections. This analysis was performed within streams and at the individual level rather than across streams at the group level, because juveniles that find suitable habitat within environments that are otherwise adverse might grow at the same rate as juveniles finding suitable habitat within high-quality environments (Nislow et al. 2004). Between May 2 and 3, 2009 (i.e., just before juvenile release), we estimated mean juvenile massat-release for each dam in our study. We collected four to 22 juveniles (mean $=14.2$ juveniles) from each dam, and each juvenile was weighed to the nearest $0.001 \mathrm{~g}$. After recapturing juveniles between August and September 2009, we modeled specific growth in the wild $\left(\Omega, \% \times\right.$ day $\left.^{-1}\right)$ following Ostrovsky (1995):

$$
\Omega=\frac{M_{t}^{b}-M_{0}^{b}}{b \cdot t} 100
$$

where $M_{0}$ is the mean weight of larvae from dam $_{m}$ estimated prior to release, $M_{\mathrm{t}}$ is the weight at recapture of a juvenile whose mother is $\operatorname{dam}_{m}, b$ is the allometric weight exponent for the relationship between specific growth rate and body weight ( 0.31 for Atlantic salmon juveniles; Elliott and Hurley 1997), and $t$ is the number of days between release and recapture. In this model, we consider the releases sites STW1 and STW2 to be the same stream, and juveniles captured on the second visit to GRV1 and STW3 were not included in the analysis. We followed the information-theoretic approach of Burnham and Anderson (2002) using a mixed analysis and maximum likelihood parameter estimation in conjunction with the corrected Akaike Information Criterion $\left(\mathrm{AIC}_{\mathrm{c}}\right)$. In our base model (in which subsequent models were nested), we assumed that dam and sire identity ( $n=41$ dams and 46 sires) contribute to variation in juvenile growth, and that average growth is different among the eight streams in our study. We hypothesized that initial egg size (dry mass, $\mathrm{mg}$ ) increases the ability of juveniles to acquire food and territories (Einum and Fleming 2000a) but that the relationship between growth and egg size would differ among streams:

$$
\begin{aligned}
Y_{i(j) m p}= & \beta_{0}+\tau_{j}+u_{0 j}+\left(\beta_{1}+u_{1 j}\right) \\
& \times x_{i(j)}+\gamma_{m}+\delta_{p}+\varepsilon_{i(j) m p},
\end{aligned}
$$

where $i$ 's are individual juveniles nested in stream $j, \beta_{0}$ is a fixed intercept, $x$ is dry egg mass $(\mathrm{mg}), \beta_{1}$ is the mean slope of growth as a function of dry egg mass across all streams, $\tau$ is the random intercept for stream $j, u_{0}$ is the random intercept modifier and $u_{1}$ is the random slope modifier for the relationship between dry egg mass and growth in stream $j, \gamma$ is the random intercept for dam $m$, $\delta$ is the random intercept for sire $p$, and $\varepsilon$ is error. This base model was then parameterized with up to five predictors (fixed effects) that might have additive effects on of juvenile growth: GI, low canopy closure, high canopy closure, velocity, and depth. These predictors reflect the physical environment within the 5-m stream section where individuals were recaptured, and every model parameterized by these predictors reflects a biologically plausible hypothesis (Burnham and Anderson 2002). Specifically, we hypothesized that low velocity decreases the ability of juveniles to acquire food items drifting in the current (Nislow et al. 1999), so we tested for a negative relationship between velocity and growth. Juveniles tend to avoid deep streams and deep sections of stream (e.g., Guay et al. 2000; Hedger et al. 2005), so we expected a negative relationship between depth and growth. Substrate size is positively correlated with the number and quality of available territories (Suttle et al. 2004; Finstad et al. 2007, 2009), so we tested for a positive relationship between individual growth and GI. A decrease in incident sunlight can decrease local productivity at small spatial scales (Murphy et al. 1986; O'Grady 1993; Riley et al. 2009), so we tested for a negative relationship between canopy closure and growth. In total, we compared 16 models. Unfortunately, due to a loss of some temperature data loggers, stream temperature could not be incorporated into our growth models, although the term $\tau$ (eq. [3]) accounts for differences in mean growth among streams.

\section{Results}

A total of 30,516 salmon were released, 1,210 juveniles were captured, and 1,084 could be assigned to their original mother. Average recapture rate per mother ranged from 0.0238 (upper confidence interval [UCI] $=0.0305$, lower confidence interval $[\mathrm{LCI}]=0.0185)$ at STW1 to 0.0478 (UCI $=0.0648$, LCI $=0.0351)$ at GRV3. Within each stream, recapture rate was positively and significantly related to egg size, and coefficients of determination $\left(r^{2}\right)$ were typically very large (table 1 ). Linear selection differ-

Figure 2: Fitness functions $\pm 95 \%$ Weibull-1 confidence intervals for egg size versus proportion of offspring recaptured. Solid arrows are minimum viable egg size, open arrows are optimal egg size. For clarity, confidence intervals are not shown on fitness functions for STW2 or STW1, where independent offspring releases (ca. 3,500 offspring) occurred at separate locations within the same stream (fig. 1). The same families and number of individuals were released in STW1 and STW2 (table A2, available online), such that the pooled sample (STW1 \& STW2) is the average offspring recapture rate in STW1 and STW2. Parameter estimates are from Weibull-1 models (eq. [1]). 

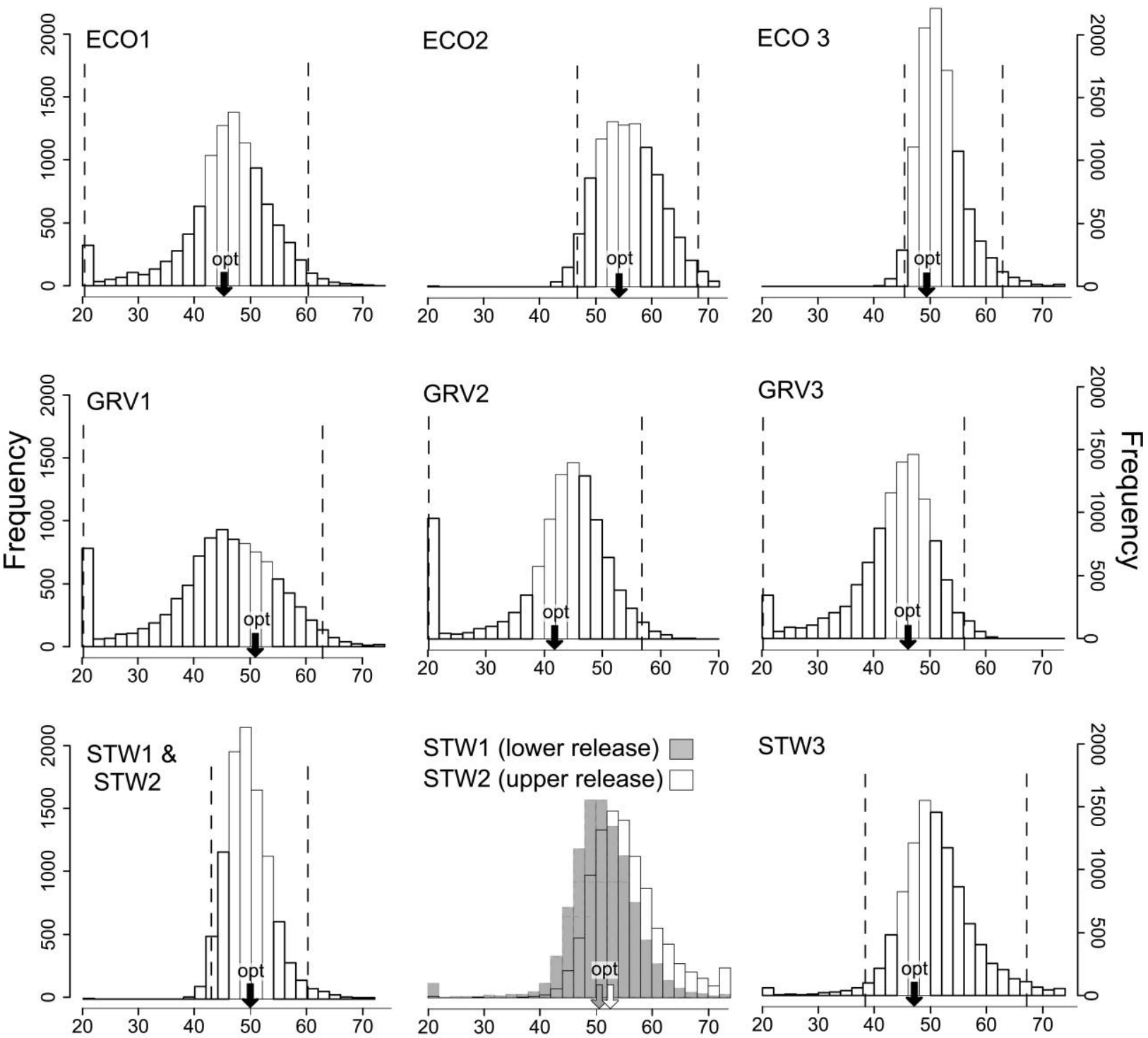

Optimal egg size (mg, dry mass)

Figure 3: Distributions of optimal egg size values for each stream arose from 10,000 simulations incorporating various sources of sampling error (see "Methods"). Solid arrows are optimal egg size estimates from Weibull-1 functions obtained using raw data (fig. 2). Dashed lines are $95 \%$ confidence intervals for optimal egg size based on simulations. For simplicity, minimum viable egg size was set at $20.0 \mathrm{mg}$, just lower than the smallest value of egg size observed in this study (which was $21.9 \mathrm{mg}$ ). Bimodal distributions (e.g., streams GRV 1, 2, and 3 ) arose when the original egg size-recapture relationship was weak (see coefficients of determination, table 1), resulting in several simulation runs in which optimal egg size was minimal due to a lack of correlation between egg size and recapture probability.

entials were also positive and significant in each stream, with $\beta \pm$ SE values ranging from $0.382 \pm 0.122$ at GRV3 to $1.26 \pm 0.138$ at ECO3 (table 1$)$ and averaging ( \pm SD) $0.690 \pm 0.299$ across all streams.

\section{Optimal Egg Size}

Estimates of optimal egg size averaged $( \pm$ SD) $48.1 \pm$ $3.78 \mathrm{mg}$ across all eight streams, and estimates ranged from
41.8 to $54.0 \mathrm{mg}$ (fig. 2). These values approach the maximum value of egg size produced by the hatchery-reared dams (mean observed egg size: $31.5 \pm 6.35 \mathrm{mg}$, range: 21.9-48.8 mg, $n=45 \mathrm{dams}$ ), and our simulations suggest that confidence limits are very wide in all cases (fig. 3 ). We found no relationship between optimal egg size and the maximum distance surveyed from the release point $\left(\right.$ optimal size $=37.6+0.0218 \times($ distance $), r^{2}=0.186$, 

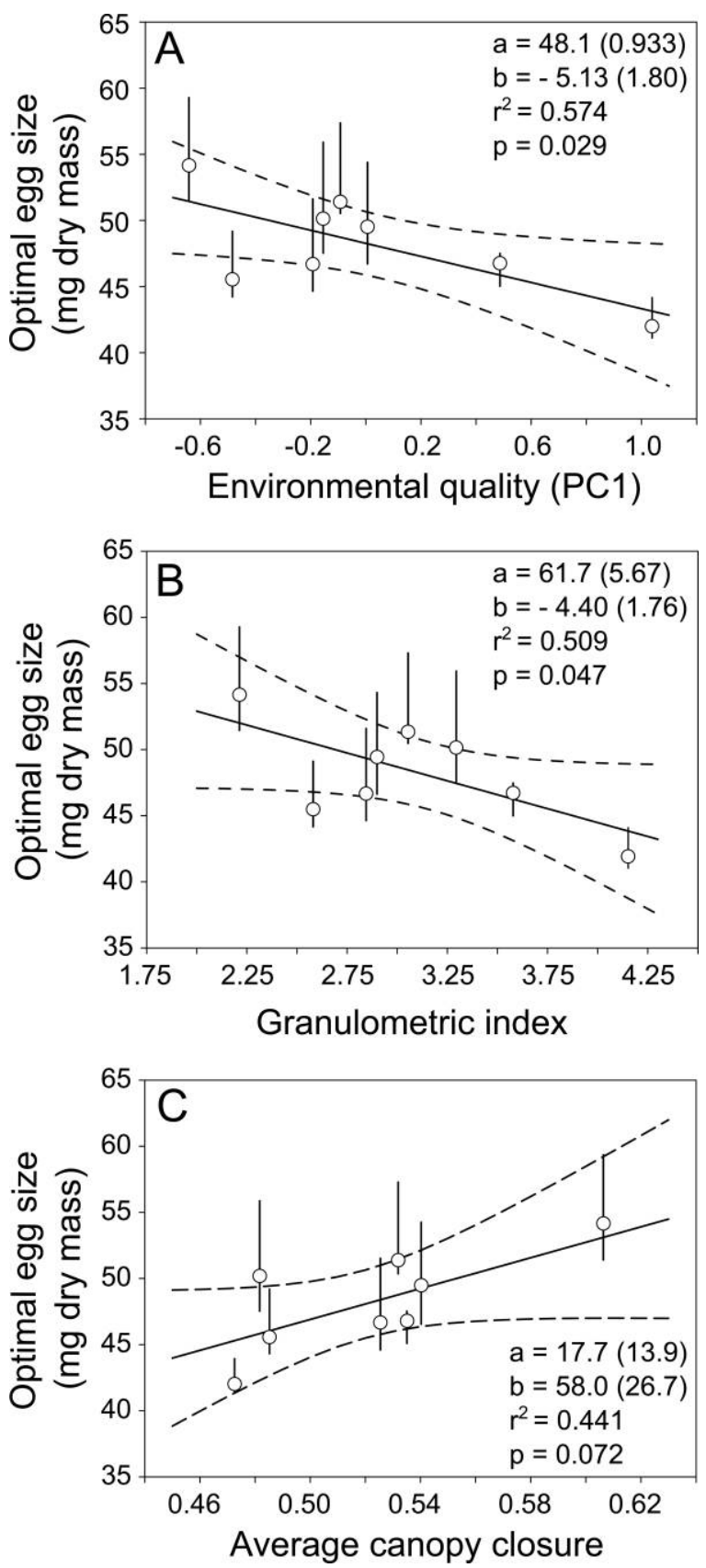

Figure 4: Relationships between optimal egg size and environmental measures of eight streams. Note that $95 \%$ confidence intervals placed on optimal egg size estimates are based on Weibull-1 models (fig. 2) and are conservative.

$n=8, P=.29)$, suggesting that potential size-biased dispersal (Einum et al. 2011) did not influence our estimates of optimal egg size. The relationship between optimal egg size and environmental quality (principal component [PC]1) was significant and negative (fig. $4 A$ ), as was the relationship between optimal egg size and GI (fig. 4B). Optimal size did not correlate with low canopy closure (optimal size $=43.8+13.0 \times$ (low canopy closure), $r^{2}=0.185, n=8, P=.29$ ) or high canopy closure (optimal size $=46.3+2.02 \times$ (high canopy closure), $r^{2}<$ $0.01, n=8, P=.92)$. However, when these two metrics were averaged to create a single index of closure (average canopy closure), this derived metric correlated positively and nearly significantly with optimal egg size (fig. 4C). Neither average stream depth (optimal size $=38.4+$ $0.593 \times($ depth $\left.), r^{2}=0.291, n=8, P=.18\right)$ nor average velocity was related to optimal egg size (optimal size $=$ $49.8-4.66 \times$ (velocity), $r^{2}<0.01, n=8, P=.92$ ).

Minimum viable egg size averaged $( \pm \mathrm{SD}) 21.9 \pm$ $3.10 \mathrm{mg}$ and ranged from 18.4 to $26.5 \mathrm{mg}$ (fig. 2). The mean and range was centered on the smallest value of egg size observed in this study, which was $21.9 \mathrm{mg}$, suggesting that our estimates of minimum viable egg size were reasonable for their respective environments. Indeed, values of minimum survival used to estimate minimum viable egg size were low (average survival at minimum viable egg size $=0.6 \% \pm 0.2 \%$, such that very few offspring survived below minimum viable size. Minimum viable egg size was not related to $k\left(r^{2}=0.064, n=8, P=.55\right)$, where $k$ is the maximum observed survival in a given stream. However, optimal egg size and minimum viable egg size were positively linearly related (optimal size $=$ $27.8+0.926 \times$ (minimum size), $r^{2}=0.580, n=8, P=$ $.028)$. Interestingly, environmental quality did not predict minimum viable egg size (minimum size $=21.8-$ $\left.3.29 \times(\mathrm{PCl}), r^{2}=0.348, n=8, P=.12\right)$, although the relationship was in the predicted direction. The strength of linear selection on offspring size $(\beta)$ was strongly related to minimum viable egg size (minimum size $=14.7+$ $\left.10.5 \times(\beta), r^{2}=0.926, n=8, P<.001\right)$, and there was also a positive but nonsignificant association between the strength of linear selection and optimal egg size (optimal size $\left.=42.4+8.16 \times(\beta), r^{2}=0.382, n=8, P=.10\right)$.

\section{Juvenile Growth}

Across all streams, mean mass-at-recapture $( \pm \mathrm{SD})$ was $1.92 \pm 0.663 \mathrm{~g}(n=996)$. Mean specific growth varied from $0.942 \% \pm 0.125 \%$ body weight $\times$ day $^{-1}$ in ECO3 $(n=94)$ to $1.32 \% \pm 0.167 \%$ body weight $\times$ day $^{-1}$ in GRV2 $(n=144)$. The model that best predicted individual growth of juveniles featured GI, low canopy closure and high canopy closure (table A6), as well as the predictors expressed in the base model (eq. [3]). Relationships between growth, GI, and canopy closure were in the direction predicted by our a priori hypotheses (table 2 ). While the Akaike weight $\left(w_{i}\right)$ for this best model was low $(0.392$, table A6), several lines of evidence suggest that it is a far superior 
Table 1: Mean estimates of optimal egg size (Opt, mg dry mass) and minimum viable egg size (Min, mg dry mass), as well as logistic regression coefficients (intercept $=a$, slope $=b$ ) and selection differentials $(\beta)$ for the relationship between egg dry mass and recapture probability

\begin{tabular}{lcccccccc}
\hline Stream & Opt & Min & $b(\mathrm{SE})$ & $a(\mathrm{SE})$ & $r^{2}$ & $\beta(\mathrm{SE})$ & $n$ & $q$ \\
\hline ECO1 & 45.3 & 20.1 & $.0412(.00820)$ & $-4.16(.280)$ & $.427^{* *}$ & $.515(.0928)$ & 117 & 36 \\
ECO2 & 54.0 & 25.9 & $.0675(.00896)$ & $-5.12(.306)$ & $.625^{* *}$ & $.947(.137)$ & 117 & \\
ECO3 & 49.4 & 26.5 & $.0719(.00770)$ & $-5.40(.264)$ & $.719^{* *}$ & $1.26(.138)$ & 94 & \\
STW1 & 52.5 & 24.1 & $.0522(.00872)$ & $-4.76(.291)$ & $.472^{* *}$ & $.859(.140)$ & 87 & 42 \\
STW2 & 50.5 & 24.7 & $.0637(.00795)$ & $-5.06(.265)$ & $.616^{* *}$ & $.810(.104)$ & 103 & \\
STW1\&2 & 49.9 & 24.0 & $.0576(.00628)$ & $-4.88(.209)$ & $.678^{* *}$ & $.830(.0933)$ & 190 & \\
STW3 & 47.1 & 20.4 & $.0520(.00853)$ & $-4.59(.284)$ & $.482^{* *}$ & $.621(.110)$ & 116 & \\
GRV1 & 50.9 & 20.8 & $.0358(.0112)$ & $-4.11(.365)$ & $.255^{*}$ & $.488(.146)$ & 102 & 32 \\
GRV2 & 41.8 & 19.3 & $.0450(.0111)$ & $-4.17(.363)$ & $.353^{* *}$ & $.479(.106)$ & 145 & \\
GRV3 & 46.1 & 18.4 & $.0476(.0148)$ & $-4.03(.486)$ & $.255^{*}$ & $.382(.122)$ & 207 & \\
\hline
\end{tabular}

Note: Sample size $(n)$ is the number of individuals in each stream that were recaptured and assigned to their original mother. The number of levels of egg size (and hence the number of dams) for each river is $q$. STW1 and STW2 are different release sites within the same stream, and STW1\&2 is the analysis on pooled data. The $R^{2}$ values are for logistic regressions, and all continuous survival probabilities were logit transformed after adding a value of 0.025 for logistic regressions. ECO, STW, and GRV = Economy, Stewiacke, and Great Village Rivers, respectively.

${ }^{*} P<.01$.

** $P<.001$.

model given the data. First, the two competitive models in our confidence set each differed from this best model by one additional parameter, but both these models had essentially the same values of log likelihood as the best model (table A6). Therefore, the more complex models are not competitive (Burnham and Anderson 2002, p. 131) but are within a few $\mathrm{AIC}_{\mathrm{c}}$ units of the best model because they feature one additional parameter without improving model fit (as measured by the log likelihood). Second, we estimated the relative importance of GI, canopy closure (as a single predictor), velocity, and depth as predictors of growth by summing $w_{i}$ across models where the appropriate predictor appears (Burnham and Anderson 2002, p. 167). We found that GI and canopy closure had a relative importance of 0.998 and 0.999 , respectively, whereas that of depth was 0.364 and that of velocity was 0.357 . Finally, effect sizes for GI and both metrics of canopy closure were always relatively large (e.g., $|t|>1.96$ in all cases), whereas those for Velocity and Depth were always relatively small (e.g., $|t|<1.96$ in all cases).

\section{Discussion}

The evolution of offspring size has been well explored in a theoretical context (e.g., Smith and Fretwell 1974; Parker and Begon 1986; Bonabeau et al. 1998; Rees and Venable 2007), yet a sound theoretical development as well as a broad understanding of this trait is ultimately founded in the empirical study of offspring size-number trade-offs. This study is the first to provide direct, empirical, quantitative support for the prediction that optimal egg size increases as environmental quality decreases. Furthermore, we find that intraspecific variation in optimal egg size is positively associated with variation in minimum viable egg size, and this provides empirical verification for theoretical studies that assume a correlation between minimum viable egg size and optimal values (McGinley et al. 1987; Einum and Fleming 2004; Olofsson et al. 2009; Charpentier et al. 2012). Our data suggest that the extent of offspring survival at low values of egg size shifts the entire fitness function toward greater or lesser values of egg size, and owing to variation in the sigmoidal shape of the fitness function, this creates a positive but unsettled association between minimum viable egg size and the optimal value (fig. 2). We also observed strong linear selection on egg size, and interestingly, the strength of selection exhibited a positive association with minimum viable egg size. This is likely because a consistent range of phenotypes was examined across all eight streams, such that low survival when egg size is small increased minimum viable egg size while concomitantly elevating the slope of the linear selection regression.

We used estimates of optimal size as a means of identifying aspects of the physical environment that comprise "environmental quality" and potentially drive the evolution of offspring provisioning strategies in Atlantic salmon. We found that the same components of the physical environment that influenced optimal egg size at a broad spatial scale also influenced individual growth of juveniles at a very small spatial scale. Juveniles that held territories in stream sections featuring relatively large gravel and a relatively open forest canopy grew relatively quickly. Similarly, across streams, the most important predictor of optimal egg size was the mean size of stream gravels (GI); 
Table 2: Summary of the model that best predicts variation in mass-specific growth $\left(\%\right.$ body weight $\times$ day $\left.^{-1}\right)$ for 996 juveniles from eight different streams in Nova Scotia

\begin{tabular}{|c|c|c|c|c|c|c|}
\hline \multirow{2}{*}{$\frac{\text { Predictor }}{\text { Sire }}$} & \multirow{2}{*}{$\begin{array}{l}\text { Effect } \\
\text { RI }\end{array}$} & \multicolumn{2}{|c|}{ Variance $(\mathrm{SD})$} & \multicolumn{2}{|c|}{ Estimate (SE) } & \multirow{2}{*}{$\begin{array}{l}t \\
\ldots\end{array}$} \\
\hline & & .00195 & $(.0441)$ & & $\ldots$ & \\
\hline Dam & RI & .00287 & $(.0535)$ & & $\ldots$ & $\ldots$ \\
\hline Site & RI & .0233 & $(.153)$ & & $\ldots$ & $\ldots$ \\
\hline Egg size by site & RS & .00000649 & $(.00255)$ & & $\ldots$ & $\ldots$ \\
\hline Residual & Error & .0194 & $(.139)$ & & $\ldots$ & $\ldots$ \\
\hline Intercept & $\mathrm{FE}$ & ... & & 1.23 & $(.0835)$ & 14.7 \\
\hline Egg size & $\mathrm{FE}$ & ... & & -.00244 & $(.00195)$ & -1.25 \\
\hline Granulometric index & $\mathrm{FE}$ & ... & & .0270 & $(.00695)$ & 3.88 \\
\hline Low canopy closure & $\mathrm{FE}$ & .. & & -.0524 & $(.0171)$ & -3.07 \\
\hline High canopy closure & $\mathrm{FE}$ & .. & & -.126 & $(.0196)$ & -6.42 \\
\hline
\end{tabular}

Note: Parameter estimates are reported after fitting models using restricted maximum likelihood parameter estimation, but maximum likelihood was used during the model selection process (table A6, available online). Random effects (intercepts $=$ RI, slopes $=$ RS) and residual variance are reported first, followed by estimates for fixed effects (FE).

mean incident sunlight (canopy closure) also correlated weakly and nearly significantly with optimal size. Water depth and velocity within stream sections did not appear to influence juvenile growth, and while stream depth and velocity were indirectly correlated with optimal egg size as principal components of environmental quality, we found that neither variable was important as an individual predictor of optimal egg size.

Understanding the evolution of egg size in any species requires identifying the life stage at which investment per offspring influences offspring performance, as well as the mechanisms through which investment-related biases in performance occur. In species with little postpartum care, effects of egg size on the performance of embryos (e.g., hatching success) are often very weak (Pepin et al. 1997; Rombough 2007; Riddick and Wu 2012; for exceptions, see Einum et al. 2002; Marshall and Bolton 2007). However, immediately following embryonic development (e.g., just after hatching), there is typically a critical period in which performance is strongly related to offspring size (Fox et al. 1997; Nislow et al. 2004; Marshall and Keough 2008). Indeed, size-biased survival of offspring is usually associated with differences in the competitive ability of juveniles (Svensson and Sinervo 2000; Bashey 2008), or with differences in the amount of time juveniles are able to persist without securing food (reviewed by Kamler 2006). Many empirical studies have verified that competition among juveniles affects the evolution of investment per offspring, primarily through its effects on juvenile resource acquisition (Hutchings 1991; Svensson and Sinervo 2000; Bashey 2008).

In this study, we focused on how the physical environment of a stream predicts environmental quality for juvenile salmon. Differences in the strength of size-biased mortality were observed among streams, likely as a result of how the physical environment affected juvenile resource acquisition immediately following release (Einum and Fleming 2000a). The size of stream substrates is a recognized driver of population regulation in Atlantic salmon, where carrying capacity and population growth rate of 1year-old fish has been linked to the presence and spatial distribution of gravel-shelter objects (Finstad et al. 2007, 2009). In part, this may occur because offspring production in salmon streams eclipses the amount of juvenile habitat that is available, such that the acquisition of a fixed, food-based territory centered within river gravels is paramount to juvenile survival (Einum and Fleming 2000b; Nislow et al. 2004; Kvingedal and Einum 2011). Failure to secure a territory usually means that juveniles become "drifters" (Bujold et al. 2004) that engage in risky foraging behavior (Vehanen 2003) and face increased mortality during their dispersal downstream (Finstad et al. 2007; Kvingedal and Einum 2011; Einum et al. 2011).

The size of stream gravel reflects the availability and quality of juvenile territories for simple geometric reasons, given that an amalgam of large gravel will have relatively more and larger intergravel spaces, and that juveniles use these gravel interstices for shelter (Heggenes 1988). Sheltering behavior is extremely important for juvenile salmon: it decreases the proportion of time spent swimming against the current, the number of aggressive encounters with conspecifics (Suttle et al. 2004), and presumably the risk of depredation. Juveniles in the vicinity of shelter objects even display resting metabolic rates lower than those not in the presence of shelters (Millidine et al. 2006). Individual growth increases with the presence and size of cover objects within juvenile territories (Suttle et al. 2004; Finstad et al. 2007), probably by virtue of lower metabolic costs, lower 
aggression among neighboring territory holders (Jaeger 1981; Suttle et al. 2004), and an increase in vulnerable prey items (invertebrates) associated with larger, less embedded gravel (Mebane 2001; Suttle et al. 2004). In this study, predicted values of optimal egg size suggest that parental reproductive success will be greater if parents decrease fecundity and increase investment per offspring when river gravel is relatively small, and this finding is highly concordant with the early life history of Atlantic salmon.

In addition, we found that the degree of canopy closure was negatively related to juvenile growth within stream sections. Negative relationships between juvenile growth, survival, and canopy closure have been previously documented at both large and small spatial scales (Murphy et al. 1986; O'Grady 1993; Riley et al. 2009). Increases in incident sunlight can stimulate the growth of periphyton, and this has the direct result of increasing local abundance of aquatic invertebrates (Zimmermann and Death 2002; Fuller et al. 2007). Therefore, juvenile salmon occupying territories in sunlit areas have greater access to food. Influxes of terrestrial invertebrates into streams are also substantial and can comprise more than $50 \%$ of the annual energy budget of stream-dwelling salmonids (Nakano and Murakami 2001; Erős et al. 2012). Incident sunlight in riparian zones may attract forest-dwelling insects to the stream and further increase food availability in sunlit areas. Interestingly, we found that optimal egg size correlated positively, but not significantly, with average stream canopy cover. This pattern warrants further investigation, as it is consistent with theoretical expectations (e.g., McGinley et al. 1987), and with broad patterns of egg size variation in relation to ecosystem productivity (Johnston and Leggett 2002).

On a cautionary note, overall survival was low and sample sizes were modest in this study. In these circumstances, it is difficult to estimate optimal egg size with accuracy (Rollinson and Hutchings 2013). Indeed, the confidence intervals estimated for predicted values of optimal egg size were also very large. We cannot discount the possibility that the correlation between optimal egg size and environmental quality is not repeatable. But we also emphasize the corroboratory nature of our data: we found that juveniles occupying areas of stream featuring more sunlight and larger gravel grew more quickly, and this complements our cross-stream analysis, which identifies gravel size and incident sunlight as potential drivers of environmental quality. Estimates of optimal egg size were also similar for STW1 and STW2, where independent releases of 3,545 juveniles occurred at different sites in the same stream. This provides limited evidence that our estimates of optimal egg size are repeatable within the environments surveyed.

\section{Acknowledgments}

We thank N. Metcalfe and an anonymous reviewer for commenting on an earlier version of this article. We thank B. Lenentine and the Canadian Department of Fisheries and Oceans for providing gametes and electrofishing equipment and both R. Farmer and R. Latta for statistical advice. Field and laboratory work could not have been accomplished without K. Crosby, P. Debes, J. Eddington, R. Farmer, A. Houde, D. Keith, M. McBride, S. Mogensen, M. Yates, and many other volunteers. Funding was provided by a Natural Sciences and Engineering Research Council of Canada (NSERC) Discovery Grant to J.A.H. and a NSERC Canada Graduate Scholarship, a President's Award, and a Killam Trust Scholarship to N.R.

\section{Literature Cited}

Achord, S., P. S. Levin, and R. W. Zabel. 2003. Density-dependent mortality in Pacific salmon: the ghost of impacts past? Ecology Letters 6:335-342.

Armstrong, J. D., and K. H. Nislow. 2006. Special section critical habitat during the transition from maternal provisioning in freshwater fish, with emphasis on Atlantic salmon (Salmo salar) and brown trout (Salmo trutta). Journal of Zoology 269:403-413.

Bailey, M. M., and M. T. Kinnison. 2010. Habitat-mediated size selection in endangered Atlantic salmon fry: selectional restoration assessment. Evolutionary Applications 3:352-362.

Bashey, F. 2008. Competition as a selective mechanism for larger offspring size in guppies. Oikos 117:104-113.

Bjornn, T. C., and D. W. Reiser. 1991. Habitat requirements of salmonids in streams. American Fisheries Society Special Publication 19:83-138.

Bohlin, T., S. Hamrin, T. Heggberget, G. Rasmussen, and S. Saltveit. 1989. Electrofishing: theory and practice with special emphasis on salmonids. Hydrobiologia 173:9-43.

Bonabeau, E., J.-L. Deneubourg, and G. Theraulaz. 1998. Withinbrood competition and the optimal partitioning of parental investment. American Naturalist 153:419-427.

Boudreault, A. 1984. Méthodologie utilisée pour la photo-interprétation des rivières à saumon de la Côte-Nord. Rapport réalisé par Gilles Shooner Inc. pour le Ministère du Loisir, de la Chasse et de la Pêche, Direction de la faune aquatique. Loretteville, Quebec.

Bujold, V., R. A. Cunjak, J. P. Dietrich, and D. A. Courtemanche. 2004. Drifters versus residents: assessing size and age differences in Atlantic salmon (Salmo salar) fry. Canadian Journal of Fisheries and Aquatic Sciences 282:273-282.

Burnham, K. P., and D. R. Anderson. 2002. Model selection and multimodel inference: a practical information-theoretic approach. 2nd ed. Springer, New York.

Charpentier, A., M. Anand, and C. T. Bauch. 2012. Variable offspring size as an adaptation to environmental heterogeneity in a clonal plant species: integrating experimental and modelling approaches. Journal of Ecology 100:184-195.

Dias, G. M., and D. J. Marshall. 2010. Does the relationship between offspring size and performance change across the life-history? Oikos 119:154-162.

Einum, S., A. G. Finstad, G. Robertsen, K. H. Nislow, S. McKelvey, 
and J. D. Armstrong. 2011. Natal movement in juvenile Atlantic salmon: a body size-dependent strategy? Population Ecology 54: 285-294.

Einum, S., and I. A. Fleming. 1999. Maternal effects of egg size in brown trout (Salmo trutta): norms of reaction to environmental quality. Proceedings of the Roval Society B: Biological Sciences 266:2095-2100.

- 2000a. Highly fecund mothers sacrifice offspring survival to maximize fitness. Nature 405:565-567.

- 2000b. Selection against late emergence and small offspring in Atlantic salmon (Salmo salar). Evolution 54:628-639.

. 2002. Does within-population variation in fish egg size reflect maternal influences on optimal values? American Naturalist 160:756-765.

- 2004. Environmental unpredictability and offspring size: conservative versus diversified bet-hedging. Evolutionary Ecology Research 6:443-455.

Einum, S., A. P. Hendry, and I. A. Fleming. 2002. Egg-size evolution in aquatic environments: does oxygen availability constrain size? Proceedings of the Royal Society B: Biological Sciences 269:23252330.

Einum, S., and K. H. Nislow. 2005. Local-scale density-dependent survival of mobile organisms in continuous habitats: an experimental test using Atlantic salmon. Oecologia (Berlin) 143:203-210.

Elliott, J., and M. A. Hurley. 1997. A functional model for maximum growth of Atlantic salmon parr, Salmo salar, from two populations in northwest England. Functional Ecology 11:592-603.

Erős, T., P. Gustafsson, L. A. Greenberg, and E. Bergman. 2012. Forest-stream linkages: effects of terrestrial invertebrate input and light on diet and growth of brown trout (Salmo trutta) in a boreal forest stream. PloS ONE 7:e36462.

Finstad, A. G., S. Einum, T. Forseth, and O. Ugedal. 2007. Shelter availability affects behaviour, size-dependent and mean growth of juvenile Atlantic salmon. Freshwater Biology 52:1710-1718.

Finstad, A. G., S. Einum, O. Ugedal, and T. Forseth. 2009. Spatial distribution of limited resources and local density regulation in juvenile Atlantic salmon. Journal of Animal Ecology 78:226-35.

Fox, C., M. Thakar, and T. Mousseau. 1997. Egg size plasticity in a seed beetle: an adaptive maternal effect. American Naturalist 149: 149-193.

Fraser, D. J., M. W. Jones, T. L. McParland, and J. A. Hutchings. 2007. Loss of historical immigration and the unsuccessful rehabilitation of extirpated salmon populations. Conservation Genetics 8:527-546.

Fuller, R. L., C. LaFave, M. Anastasi, J. Molina, H. Salcedo, and S. Ward. 2007. The role of canopy cover on the recovery of periphyton and macroinvertebrate communities after a month-long flood. Hydrobiologia 598:47-57.

Guay, J. C., D. Boisclair, D. Rioux, M. Leclerc, M. Lapointe, and P. Legendre. 2000. Development and validation of numerical habitat models for juveniles of Atlantic salmon (Salmo salar). Canadian Journal of Fisheries and Aquatic Sciences 57:2065-2075.

Hedger, D. R., J. J. Dodson, N. E. Bergeron, and F. Caron. 2005. Habitat selection by juvenile Atlantic salmon: the interaction between physical habitat and abundance. Lournal of Fish Biology 67: 1054-1071.

Heggenes, J. 1988. Substrate preferences of brown trout fry (Salmo trutta) in artificial stream channels. Canadian Journal of Fisheries and Aquatic Sciences 45:1801-1806.

Hendry, A. P., T. Day, and A. B. Cooper. 2001. Optimal size and number of propagules: allowance for discrete stages and effects of maternal size on reproductive output and offspring fitness. American Naturalist 157:387-407.

Houde, A. L. S., D. J. Fraser, P. O’Reilly, and J. A. Hutchings. $2011 a$. Maternal and paternal effects on fitness correlates in outbred and inbred Atlantic salmon (Salmo salar). Canadian Journal of Fisheries and Aquatic Sciences 68:534-549.

. 2011b. Relative risks of inbreeding and outbreeding depression in the wild in endangered salmon. Evolutionary Applications 4:634-647.

Hurlbert, S. H. 1984. Pseudoreplication and the design of ecological field experiments. Ecological Monographs 54:187-211.

Hutchings, J. A. 1991. Fitness consequences of variation in egg size and food abundance in brook trout Salvelinus fontinalis. Evolution 45:1162-1168.

Hutchings, J. A. 1997. Life history responses to environmental variability in early life. Pages 139-168 in R. C. Chambers and E. A. Trippel, eds. Early life history and recruitment in fish populations. Chapman \& Hall, London.

Jaeger, R. G. 1981. Dear enemy recognition and the costs of aggression between salamanders. American Naturalist 117:962-974.

Johnson, D. W., M. R. Christie, and J. Moye. 2010. Quantifying evolutionary potential of marine fish larvae: heritability, selection, and evolutionary constraints. Evolution 64:2614-2628.

Johnston, T. A., and W. C. Leggett. 2002. Maternal and environmental gradients in the egg size of an iteroparous fish. Ecology 83:17771791.

Kamler, E. 2006. Parent-egg-progeny relationships in teleost fishes: an energetics perspective. Reviews in Fish Biology and Fisheries 15:399-421.

Kane, T. R. 1988. Relationship of temperature and time of initial feeding of Atlantic salmon. Progressive Fish-Culturist 50:93-97.

Kvingedal, E., and S. Einum. 2011. Prior residency advantage for Atlantic salmon in the wild: effects of habitat quality. Behavioral Ecology and Sociobiology 65:1295-1303.

Lack, D. 1947. The significance of clutch-size. Ibis 89:302-352.

Lande, R., and S. J. Arnold. 1983. The measurement of selection on correlated characters. Evolution 37:1210-1226.

Levin, P. S., S. Achrod, B. E. Feist, and R. W. Zabel. 2002. Nonindigenous brook trout and the demise of Pacific salmon: a forgotten threat? Proceedings of the Roval Society B: Biological Sciences 269:1663-1670.

Marshall, D. J., and T. F. Bolton. 2007. Effects of egg size on the development time of non-feeding larvae. Biological Bulletin 212: 6-11.

Marshall, D. J., and M. J. Keough. 2008. The relationship between offspring size and performance in the sea. American Naturalist 171:214-224.

- 2009. Does interspecific competition affect offspring provisioning? Ecology 90:487-495.

McGinley, M. A., D. H. Temme, and M. A. Geber. 1987. Parental investment in offspring in variable environments: theoretical and empirical considerations. American Naturalist 130:370-398.

Mebane, C. A. 2001. Testing bioassessment metrics: macroinvertebrate, sculpin, and salmonid responses to stream habitat, sediment, and metals. Environmental Monitoring and Assessment 67:293322.

Millidine, K. J., J. D. Armstrong, and N. B. Metcalfe. 2006. Presence of shelter reduces maintenance metabolism of juvenile salmon. Functional Ecology 20:839-845. 
Murphy, M. L., J. Heifetz, S. W. Johnson, K. V. Koski, and J. F. Thedinga. 1986. Effects of clear-cut logging with and without buffer strips on juvenile salmonids in Alaskan streams. Canadian Journal of Fisheries and Aquatic Sciences 43:1521-1533.

Mäki-Petays, A., A. Huusko, J. Erkinaro, and T. Muotka. 2002. Transferability of habitat suitability criteria of juvenile Atlantic salmon (Salmo salar). Canadian Journal of Fisheries and Aquatic Sciences 59:218-228.

Nakano, S., and M. Murakami. 2001. Reciprocal subsidies: dynamic interdependence between terrestrial and aquatic food webs. Proceedings of the National Academy of Sciences of the USA 98:166170.

Nislow, K. H., S. Einum, and C. L. Folt. 2004. Testing predictions of the critical period for survival concept using experiments with stocked Atlantic salmon. Journal of Fish Biology 65(suppl. 1):188200.

Nislow, K. H., C. L. Folt, and D. L. Parrish. 1999. Favorable foraging locations for young Atlantic salmon: application to habitat and population restoration. Ecological Applications 9:1085-1099.

Olofsson, H., J. Ripa, and N. Jonzén. 2009. Bet-hedging as an evolutionary game: the trade-off between egg size and number. Proceedings of the Roval Society B: Biological Sciences 276:2963-2969.

Ostrovsky, I. 1995. The parabolic pattern of animal growth: determination of equation parameters and their temperature dependencies. Freshwater Biology 33:357-371.

O'Grady, M. F. 1993. Initial observations on the effects of varying levels of deciduous bankside vegetation on salmonid stocks in Irish waters. Aquaculture and Fisheries Management 24:563-573.

O’Reilly, P. T., and C. J. Harvie. 2009. Conservation of genetic variation in the inner Bay of Fundy Atlantic salmon captive breeding and rearing program. Canadian Science Advisory Secretariat Research Document 2009/095. Department of Fisheries and Oceans, Dartmouth, Nova Scotia.

Parker, G. A., and M. Begon. 1986. Optimal egg size and clutch size: effects of environment and maternal phenotype. American Naturalist 128:573-592.

Pepin, P., D. C. Orr, and J. T. Anderson. 1997. Time to hatch and larval size in relation to temperature and egg size in Atlantic cod (Gadus morhua). Canadian Journal of Fisheries and Aquatic Sciences 54(suppl. 1):2-10.

Purchase, C., and J. Hutchings. 2008. A temporally stable spatial pattern in the spawner density of a freshwater fish: evidence for an ideal despotic distribution. Canadian Journal of Fisheries and Aquatic Sciences 65:382-388.

R Development Core Team. 2012. R: a language and environment for statistical computing. R Foundation for Statistical Computing. Vienna, Austria. http://www.R-project.org,.

Rees, M., and L. D. Venable. 2007. Why do big plants make big seeds? Journal of Ecology 95:926-936.

Riddick, E. W., and Z. Wu. 2012. Mother-offspring relations: prey quality and maternal size affect egg size of an acariphagous lady beetle in culture. Psyche: A Journal of Entomology 2012:1-7.

Riley, W. D., M. G. Pawson, V. Quayle, and M. J. Ives. 2009. The effects of stream canopy management on macroinvertebrate communities and juvenile salmonid production in a chalk stream. Fisheries Management and Ecology 16:100-111.

Ritz, C., and J. Strebig. 2011. drc: analysis of dose-response curves. Retrieved from http://cran.r-project.org/.
Rollinson, N., and J. A. Hutchings. 2010. Why does egg size increase with maternal size? effects of egg size and egg density on offspring phenotypes in Atlantic salmon (Salmo salar). Evolutionary Ecology Research 12:949-960.

Rollinson, N., and J. A. Hutchings. 2011a. Body size-specific maternal effects on the offspring environment shape juvenile phenotypes in Atlantic salmon. Oecologia (Berlin) 166:889-898.

- 2011b. Why does egg size of salmonids increase with the mean size of population spawning gravels? Canadian Journal of Fisheries and Aquatic Sciences 68:1307-1315.

- 2013. The relationship between offspring size and fitness: integrating theory and empiricism. Ecology 94:315-324.

Rollinson, N., R. G. Farmer, and R. J. Brooks. 2012. Widespread reproductive variation in North American turtles: temperature, egg size and optimality. Zoology 115:160-169.

Rombough, P. J. 2007. Oxygen as a constraining factor in egg size evolution in salmonids. Canadian Journal of Fisheries and Aquatic Sciences 64:692-699.

Sinervo, B., K. Zamudio, P. Doughty, and R. B. Huey. 1992. Allometric engineering: a causal analysis of natural selection on offspring size. Science 258:1927-1930.

Smith, C., and S. Fretwell. 1974. The optimal balance between size and number of offspring. American Naturalist 108:499-506.

Steingrimsson, S. O., and J. W. A. Grant. 2003. Patterns and correlates of movement and site fidelity in individually-tagged young-of-theyear Atlantic salmon (Salmo salar). Canadian Journal of Fisheries and Aquatic Sciences 60:193-202.

Suttle, K. B., M. E. Power, J. M. Levine, and C. McNeely. 2004. How fine sediment in riverbeds impairs growth and survival of juvenile salmonids. Ecological Applications 14:969-974.

Svärdson, G. 1949. Natural selection and egg number in fish. Pages 115-122 in Report 29. Institute of Freshwater Research, Drottningholm, Sweden.

Svensson, E., and B. Sinervo. 2000. Experimental excursions on adaptive landscapes: density-dependent selection on egg size. Evolution 54:1396-1403.

Taborsky, B. 2006. Mothers determine offspring size in response to own juvenile growth conditions. Biology Letters 2:225-228.

Tymchuk, W. V., P. O'Reilly, J. Bittman, D. Macdonald, and P. Schulte. 2010. Conservation genomics of Atlantic salmon: variation in gene expression between and within regions of the Bay of Fundy. Molecular Ecology 19:1842-1859.

Vehanen, T. 2003. Adaptive flexibility in the behaviour of juvenile Atlantic salmon: short-term responses to food availability and threat from predation. Iournal of Fish Biology 63:1034-1045.

Webb, J. H., R. J. Fryer, J. B. Taggart, C. E. Thompson, and A. F. Youngson. 2001. Dispersion of Atlantic salmon (Salmo salar) fry from competing families as revealed by DNA profiling. Canadian Journal of Fisheries and Aquatic Sciences 58:2386-2395.

Zar, J. H. 1984. Biostatistical analysis. 2nd ed. Prentice-Hall, London. Zimmermann, E. M., and R. G. Death. 2002. Effect of substrate stability and canopy cover on stream invertebrate communities. New Zealand Journal of Marine and Freshwater Research 36:537545.

Associate Editor: Thomas N. Sherratt Editor: Mark A. McPeek 